\title{
Novel compound heterozygous mutations in WDR62 gene leading to developmental delay and Primary Microcephaly in Saudi Family
}

\author{
Muhammad Imran Naseer ${ }^{1}$, Mahmood Rasool ${ }^{2}$, \\ Angham Abdulrahman Abdulkareem ${ }^{3}$, Adeel G. Chaudhary ${ }^{4}$, \\ Syed Kashif Zaidi ${ }^{5}$, Mohammad H. Al-Qahtani ${ }^{6}$
}

\begin{abstract}
Objective: Primary microcephaly $(\mathrm{MCPH})$ is a rare autosomal recessive disorder characterized by impaired congenital reduction of brain size along with head circumference and intellectual disability. MCPH is a heterogeneous disorder and more than twenty four genes associated with this disease have been identified so far. The objective of this study was to find out the novel genes or mutations leading to the genetic defect in a Saudi family with primary microcephaly.

Methods: Whole exome sequencing was carried out to find the novel mutation and the results was further validated using Sanger sequencing analysis. This study was done in the Center of excellence in Genomic Medicine and Research, King Abdulaziz University under KACST project during 2017 and 2018.

Results: We report a novel compound heterozygous mutations C.797C $>\mathrm{T}$ in exon 7 and c.1102G $>\mathrm{A}$ in exon 9 of the WD repeat domain 62 (WDR62) (OMIM 604317) gene in two affected siblings in Saudi family with intellectual disability, speech impediments walking difficulty along with primary microcephaly. Two rare, missense variants were detected in heterozygous state in the WDR62 gene in these two affected individuals from the heterozygous parents.

Conclusions: A compound heterozygous mutations c.797C $>T$ in exon 7 and c.1102G $>A$ in exon 9 of the WDR62 gene was identified. WDR62 gene is very important gene and mutation can lead to neuro developmental defects, brain malformations, reduced brain and head size. These results should be taken into consideration during prognostic discussions and mutation spectrum with affected patients and their families in the Saudi population.
\end{abstract}

KEYWORDS: Compound heterozygous mutation, Primary Microcephaly, Saudi Family, WDR62.

doi: https://doi.org/10.12669/pjms.35.3.36

How to cite this:

Naseer MI, Rasool M, Abdulkareem AA, Chaudhary AG, Zaidi SK, Al-Qahtani MH. Novel compound heterozygous mutations in WDR62 gene leading to developmental delay and Primary Microcephaly in Saudi Family. Pak J Med Sci. 2019;35(3):764-770. doi: https://doi.org/10.12669/pjms.35.3.36

This is an Open Access article distributed under the terms of the Creative Commons Attribution License (http://creativecommons.org/licenses/by/3.0), which permits unrestricted use, distribution, and reproduction in any medium, provided the original work is properly cited.

Correspondence:

Dr. Muhammad Imran Naseer,

Associate Professor,

Center of Excellence in Genomic Medicine Research (CEGMR),

King Abdulaziz University,

21589, Jeddah,

Kingdom of Saudi Arabia.

Email: mimrannaseer@yahoo.com minaseer@kau.edu.sa

* Received for Publication:

* $1^{\text {st }}$ Revision Received:

* $2^{\text {nd }}$ Revision Received:

* Final Revision Accepted:
September 27, 2018

November 20, 2018

March 11, 2019

March 18, 2019

\section{INTRODUCTION}

The autosomal recessive form of primary microcephaly $(\mathrm{MCPH})$ is a rare genetic disorder that is characterized by head circumference less than three standard deviation below the mean from age and sex associated with mild to severe intellectual disability. ${ }^{1}$ Twenty four genes MCPH1MCPH24 have been reported so far those may be involved in the underlying cause of autosomal recessive primary microcephaly. However, Most of the mutations have been reported in two abnormal 
spindle microtubule assembly (ASPM) OMIM 608716 genes accounting for more than half of all mutations; and WDR62 gene around 10\% of all reported cases related to primary microcephaly. ${ }^{2}$

WD repeat domain 62 genes (WDR62 - GenBank Accession NM_005682.5) are known to play important role in cerebral cortical development and any mutations in this gene lead to cortical malformations, mental retardation and primary microcephaly. Recently a compound heterozygous mutations c.731 C > T (p.Ser 244 Leu) and c.2413 G > T (p.Glu $805 \mathrm{X}$ ) in the WDR62 gene responsible for the mitotic centrosomal protein WDR62, in a microcephaly family from Japanese. ${ }^{3}$ We have also reported in our recent study a missense mutation in exon 30 of WDR62changing alanine to aspartate in the protein leading to the typical MCPH2 phenotype. ${ }^{4}$ Whereas new homozygous splicing variantc. $3335+1 \mathrm{G}>\mathrm{C}$ in the WDR62 gene also reported recently. ${ }^{5}$

Previously pathogenic mutations reported in WDR62 include missense (e.g. W224S; E526K; $\mathrm{R} 438 \mathrm{H}$ ) and truncating mutations (e.g. Q470X; Val1402GlyfsTer12; 2083delA; 2472_2473delAG; Gly1280AlafsTer21; c.2527dupG; p.R438H; c.390G>A; p.D955Afs*112). ${ }^{6-12}$ In this study two rare, missense variants were detected as compound heterozygous state in the WDR62 gene of these patients results as c.797C $>\mathrm{T}$, exon 7 (Ala266Val) and c.1102G>A, exon 9 (Asp368Asn) and these mutation leading to the typical MCPH2 MIM 604317 phenotype in Saudi family. The human genome contains two copies of each gene, a paternal and a maternal allele. A mutation affecting only one allele is called heterozygous and affecting both allele called compound heterozygous mutation and if we find any mutation affecting both allele may lead to the disease phenotype. Interestingly, both variants are predicted to be deleterious by the majority of in silico prediction tools and are rare in the general population.

\section{METHODS}

Sample Collections: The detailed pedigree (family chart) was drawn after obtaining all the available information from the family as shown in (Fig.1). Detailed written informed consent was taken from all family members and parents before the extraction of blood. This study was approved by the ethical committee of the Center of Excellence in Genomic Medicine Research, King Abdulaziz University Jeddah. The blood samples were collected in the EDTA tube from father, mother and two affected girls. The affected members were under medical examination at Taif Hospital, Saudi Arabia.

Patient 1 (IV-1): Patient 1 (IV-1) was 11 years old girl at the time of examination and blood

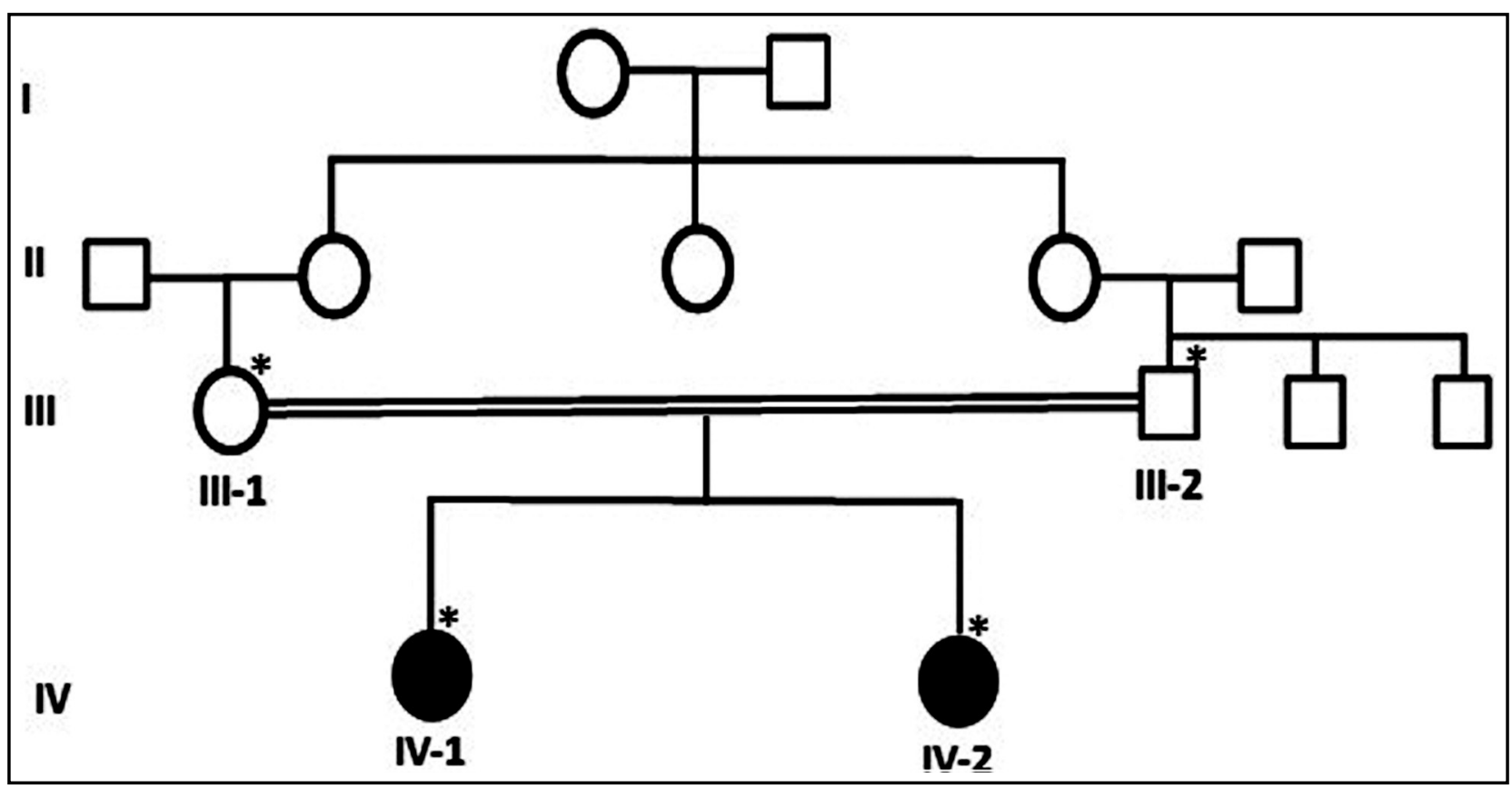

Fig.1: A pedigree of a consanguineous Saudi family representing the primary microcephaly phenotype segregating in an autosomal recessive manner. The samples available for genetic testing are marked with asterisks.

Whole exome sequencing was done for IV-1 affected member of the family. 
extraction. She presented with proptosis, delayed speech, developmental delay, dysmorphic features and microcephaly. Head circumference was 48 $\mathrm{cm}<1$ percentile $-3.8 \mathrm{SD}$. She also have tumor in the chest cage. She had no other neurological problem such as progressive cognitive decline, seizures and spasticity.

Patient 2 (IV-2): Patient 2 (IV-2) was also a 9 years old girl. She had dysmorphic features and developmental delay also has speech problem along with microcephaly. She also has delayed in walking (walking started at the age of 4 years) and was unable to express her feeling. The head circumference was $(48 \mathrm{~cm}<1$ percentile $(-3.2 \mathrm{SD})$. She had no other neurological finding, such as seizures, spasticity, or progressive cognitive decline. The phenotype were similar to the previously reported patients associated with WDR62 gene for primary microcephaly.

\section{Magnetic resonance imaging (MRI) Examination:}

Patient (IV-1): MRI examination reports multiple bilateral abnormal MR signal foci of viable shape are seen involving the fronto-parieto-occipital region some of them have gyriform pattern. They display high signal in T2 and Fluid-attenuated inversion recovery (FALIR) with restriction in diffusionweighted imaging (DWIs). The MRI finding rises possibility of ischemic insult. Prominent ventricles and extra axial cerebrospinal fluid (CSF) spaces with no middle shift or deformity was seen. There was no evidence of mass lesion and gross vascular abnormality. Normal cerebellum, brain stem and cervico - medullary junction was seen with normal sellar region.

Patient (IV-2): MRI findings report bilateral cortical and subcortical abnormal MR signal patchy area involving occipital region more on right side with mild ischemic insult. They display high signal in T2 and FALIR with faint restriction in DWIs. Normal size shape and position of the ventricles with middle shift or deformity was seen. There was no evidence of mass lesions and gross vascular abnormality. Normal cerebellum, brain stem and cervico - medullary junction were seen with normal sellar region and normal extra axial spaces.

Whole exome sequencing: Whole exome sequencing was done to identify the pathogenic mutation related to the primary microcephaly. DNA quality and concentration was measured by using $1 \%$ agarose gel, $30 \mathrm{~min}$ running at $100 \mathrm{~V}, 0.5 \mathrm{ul}$ of DNA loaded volume. The samples for exome sequencing were prepared according to an Agilent SureSelect
Target Enrichment Kit preparation guide (Capture kit, SureSelect V6-Post) and the constructed libraries were prepared and then sequenced using Illumina HiSeq 2000/2500 sequencer. The resulting variant call format (VCF) file contains 107840 variants. These variants were filtered based on frequency, quality, genomic position, protein effect, pathogenicity and based on previous associations with the disease phenotype. We didn't find any pathogenic variant detected in the known microcephaly genes except we find the compound heterozygous mutation in WDR62 gene.

Sanger sequencing: To further confirm the mutation found in whole exome sequencing in the affected members and in the patients Sanger sequencing using Applied Biosystems 3500 (CA, USA) Sequencer (ABI 3500) was performed. To confirm the mutation as pathogenic, we also sequenced this DNA variant in unrelated 100 health control people. WDR62 gene was amplified by polymerase chain reaction (PCR). PCR products purified and further subjected to cycle sequencing reactions by using BigDye Terminator V3.1 Cycle Sequencing kit to detect any mutation.

In silico analysis and functional prediction of these mutations were analyzed using the available online prediction software tolls that includes, Mutation Taster, PolyPhen-2 (http://genetics.bwh.harvard. edu/pph2/) PROVEAN/SIFT (http://provean. jcvi.org/) and PhastCons (http://compgen.cshl. edu/phast/) etc.

\section{RESULTS}

Compound Heterozygous Mutations in WDR62 Identified through Exome Sequencing: Whole exome sequencing revealed two rare, missense variants detected in heterozygous state in the WDR62 gene of this patient. The compound heterozygous missense mutations were in exon 7 and 9 of WDR62 gene in both affected individuals where c.797C $>$ T, p.(Ala266Val) and c.1102G $>$ A, p.(Asp368Asn).Two rare, missense variants were detected in compound heterozygous state in the WDR62 gene of two affected patient with primary microcephaly. DNA analysis of parents and affected family members was used to verify cosegregation of the identified variants with the phenotype and establish a compound heterozygous state of these variants. Segregation analysis was done to determine whether these variants are present in compound heterozygous state. Our results showed a compound heterozygous mutation in 
Naseer et al.

Table-I: Mutation spectrum of WDR62 gene mutations known until now.19-23

\begin{tabular}{|c|c|c|c|c|c|c|}
\hline $\begin{array}{l}\text { S. } \\
\text { No. }\end{array}$ & Mutation & Ethnicity & Mutation & $\begin{array}{l}\text { Alteration } \\
\text { Type }\end{array}$ & Exon/Intron & Reference \\
\hline 1 & c. $28 \mathrm{G}>\mathrm{T}$ & - & Missense & p.Ala10Ser & Exon 1 & 19 \\
\hline 2 & c. $189 \mathrm{G}>\mathrm{T}$ & - & Missense & p.Glu63Asp & Exon 2 & 19 \\
\hline 3 & c. $193 \mathrm{G}>\mathrm{A}$ & Arab & Missense & p.Val65Met & Exon 2 & 8,14 \\
\hline 4 & c. $332 \mathrm{G}>\mathrm{C}$ & Pakistani & Missense & p.Arg111Thr & Exon 3 & 2 \\
\hline 5 & c.363delT & Mexican & Frameshift & p.Asp112MetfsX5 & Exon 4 & 14 \\
\hline 6 & c. $390 \mathrm{G}>\mathrm{A}$ & Sudanese & Missense & p.Glu130Glu & Exon 4 & 12 \\
\hline 7 & c.535_536insA & Indian & Frameshift & p.Met179fsX21 & Exon 5 & 16 \\
\hline 8 & c. $617 \mathrm{G}>\mathrm{C}$ & - & Missense & p.Trp224Ser & Exon 6 & 7 \\
\hline 9 & c. $731 \mathrm{C}>\mathrm{T} /$ c. $2413 \mathrm{G}>\mathrm{T}$ & Japan & Missense & $\begin{array}{l}(\text { p.Ser } 244 \text { Leu }) / \\
(\text { p.Glu } 805 \text { X) }\end{array}$ & Exon 7/20 & 3 \\
\hline 10 & c. $797 \mathrm{C}>\mathrm{T} / \mathrm{c} .1102 \mathrm{G}>\mathrm{A}$ & Saudi & Missense & $\begin{array}{l}\text { p.Ala266Val/ } \\
\text { p.Asp368Asn }\end{array}$ & Exon7/9 & $\begin{array}{l}\text { Present } \\
\text { Study }\end{array}$ \\
\hline 11 & c. $900 \mathrm{C}>\mathrm{A}$ & Indian & Nonsense & p.Cys300X & Exon 8 & 16 \\
\hline 12 & c. $1043+1 \mathrm{G}>\mathrm{A}$ & Turkish & Splicesite & p.Ser348RfsX63 & Intron 8 & 14 \\
\hline 13 & c.1143delA & Pakistani & Frameshift & p.H381PfsX48 & Exon 9 & 23 \\
\hline 14 & c. $1194 \mathrm{G}>\mathrm{A}$ & Pakistani & Missense & p.Trp398 & Exon 9 & 2 \\
\hline 15 & c. $1198 \mathrm{G}>\mathrm{A}$ & - & Missense & p.E400K & Exon 9 & 20 \\
\hline 16 & $\begin{array}{l}\text { c. } 1313 \mathrm{G}>\mathrm{A} / \\
\text { c. } 2864-2867 \mathrm{del} A C A G\end{array}$ & German & $\begin{array}{l}\text { Missense/ } \\
\text { Frameshift }\end{array}$ & $\begin{array}{l}\text { (p.R438H) / } \\
\text { (p.D955Afs*112) }\end{array}$ & Exon $10 / 22$ & 10 \\
\hline 17 & c. $1313 \mathrm{G}>\mathrm{A}$ & - & Missense & p.Arg438His & Exon 10 & 8 \\
\hline 18 & c. $1408 \mathrm{C}>\mathrm{T}$ & - & Nonsense & p.Gln $470 X$ & Exon 11 & 7 \\
\hline 19 & c. $1531 \mathrm{G}>\mathrm{A}$ & Pakistani & Missense & p.Asp511Asn & Exon 11 & 8 \\
\hline 20 & c. $1576 \mathrm{G}>\mathrm{T}$ & - & Nonsense & p.Glu526X & Exon 12 & 7 \\
\hline 21 & c. $1576 \mathrm{G}>\mathrm{A}$ & - & Missense & p.Glu526Lys & Exon 12 & 7 \\
\hline 22 & c.1605_1606InsT & Turkish & Nonsense & p.Glu536X & & 18 \\
\hline 23 & c.1821dupT & French Canadian & Frameshift & p.Arg608Serfs*26 & Exon 14 & 21 \\
\hline 24 & c. 1942 C>T & Pakistani & Missense & p.Gln648X & Exon 15 & 22 \\
\hline 25 & $\begin{array}{l}\text { c. } 2083 \text { delA/ } \\
\text { c. } 2472 \_2473 \text { delAAG }\end{array}$ & - & Frameshift & p.S696fs/p.Q918fs & Exon17/23 & 9 \\
\hline 26 & c. $2527 \mathrm{dupG}$ & Pakistani & Frameshift & p.Asp843GlyfsX3 & Exon 21 & 11 \\
\hline 27 & c. $2867+4 \_c 2867+7$ delGGTG & Turkish & Frameshift & p.Ser956CysfsX38 & Intron 23 & 14 \\
\hline 28 & c. $3232 \mathrm{G}>\mathrm{A}$ & Pakistani & Missense & p.Ala1078Thr & Exon 27 & 8 \\
\hline 29 & c. $3335+1 G>C$ & Italian & Splicesite & - & - & 5 \\
\hline 30 & c.3361delG & Pakistani & Frameshift & p.Ala1121Glnfs*6 & Exon 28 & 2 \\
\hline 31 & c. $3503 \mathrm{G}>\mathrm{A}$ & Pakistani & Missense & p.Trp1168* & Exon 29 & 2 \\
\hline 32 & $\begin{array}{l}\text { c.3839_3855delGCC } \\
\text { AAGAGCCTGCCCTG }\end{array}$ & Pakistani & Frameshift & p.Gly1280AlafsX21 & Exon 30 & 7 \\
\hline 33 & c. $3878 \mathrm{C}>\mathrm{A}$ & Saudi & Missense & p.Ala1293Asp & Exon 30 & 4 \\
\hline 34 & $\begin{array}{l}\text { c.3936dupC/ } \\
\text { 3936_3937incC }\end{array}$ & $\begin{array}{l}\text { Caucasian } \\
\text { Turkish } \\
\text { Pakistani }\end{array}$ & Frameshift & $\begin{array}{l}\text { p.Val1314ArgfsX18/ } \\
\text { Val1314GlyfsX17 }\end{array}$ & Exon 30 & 8,14 \\
\hline 35 & c.4205delTGCC & Turkish & Frameshift & p.Val1402GlyfsX12 & Exon 31 & 7 \\
\hline 36 & c.4241dupT & Pakistani & Frameshift & p.Leu1414LeufsX41 & Exon 31 & 8 \\
\hline
\end{tabular}

WDR62gene in exon 7 and 9 in the two affected girls. All the mutation for WDR62 gene known so far is represented in Table-I.

Sanger sequencing: Our Sanger sequencing results showed a compound heterozygous mutation in MCPH1 gene where at 982 (c.982G>A) and at position 1273 (c.1273T>A) in exon 8 of the both affected IV-1, and IV-2 proband whereas the one parent was heterozygous at one position while other was heterozygous at other position as shown in (Fig.2). The found mutation was further validated in 100 control samples, but no one has this sequence 


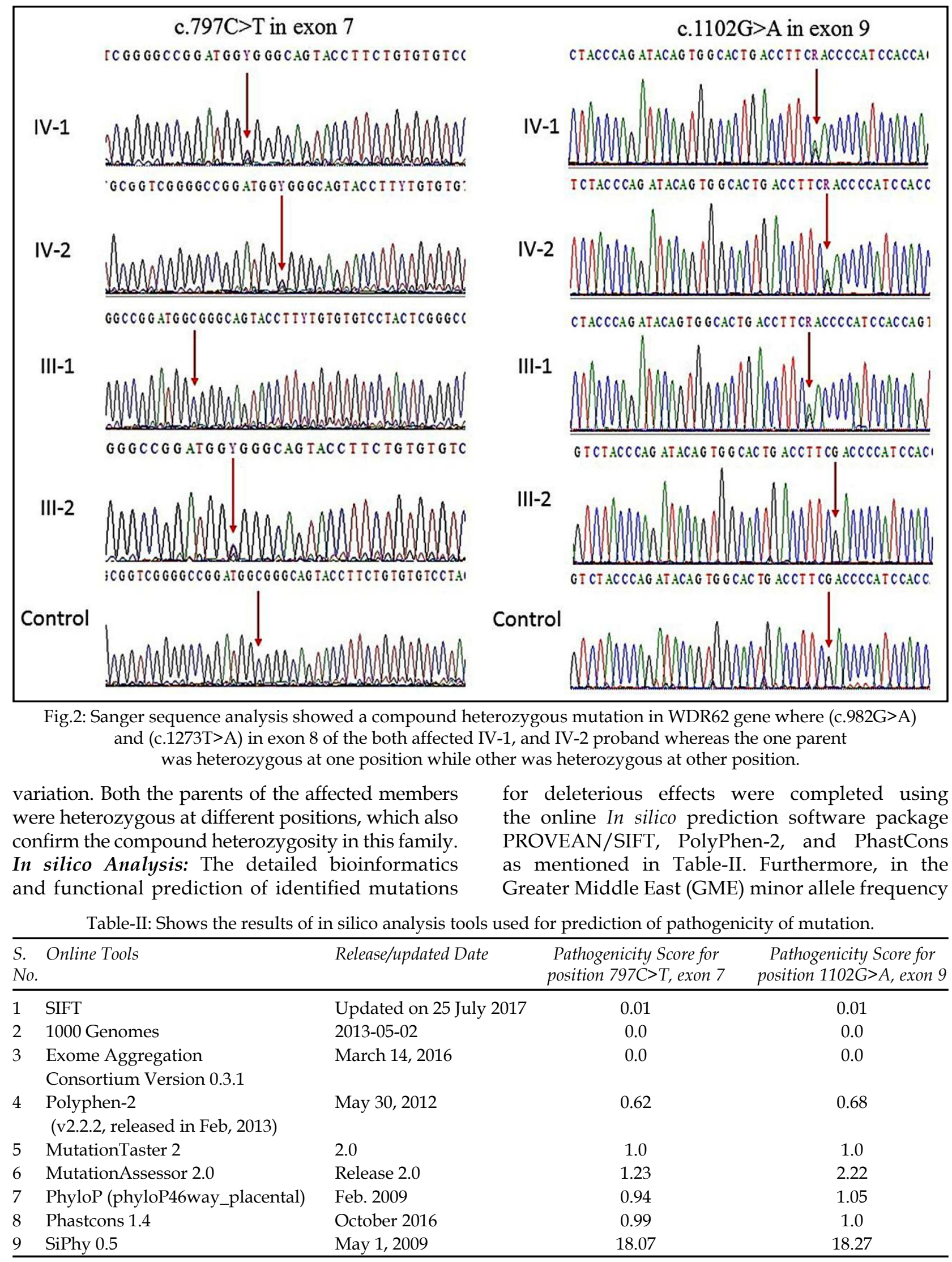


was 0.00 in the database. Further, SIFT 0.12, PolyPhen 0.7, PhyloP (phyloP46way_placental) MutationAssessor 2.0 (0.9) and Mutation Tester $(-0.99)$ predicted this variation as disease causing mutation. This mutations was not reported in the Human Gene Mutation database (HGMD, www.hgmd.cf.ac.uk/) and Online Mendelian Inheritance in Man (MIM/OMIM). 1000 genome (http://www.internationalgenome.org/) and The Exome Aggregation Consortium (ExAc) (Version 0.3.1) (http://exac.broadinstitute.org/) data base. All of the software's predicted this mutation to be disease causing and lethal for overall proper functioning of the protein as shown in Table-II.

\section{DISCUSSION}

WDR62 encodes a protein which is required for cerebral cortical development and neurogenesis. ${ }^{13}$ It is proposed to play a role in neuronal migration and proliferation. ${ }^{7,14}$ The Wdr62 expression was found to developing mouse brain, with maximum expression in the forebrain. ${ }^{14} \mathrm{Wdr62}$ gene genetically interacts with Aurora A to regulate mitotic progression, spindle formation and maintaining the size of brain. Whereas loss of these gene interactions leads to delay in mitosis and cell death of neural progenitor cells (NPCs) which may cause of human primary microcephaly. ${ }^{15}$

Mutations in WDR62 have been associated with primary microcephaly 2 (MCPH2), with or without cortical malformations. ${ }^{14,16,17}$ This is a disease characterized by microcephaly associated with other manifestation and showing a wide phenotypic variability. ${ }^{18}$ Associated features include modest to severe mental retardation, and numerous type of cortical malformations in patients with primary microcephaly. Cortical malformations may include cortical thickening, pachygyria lissencephaly, microgyria, schizencephalyhypoplasia of the corpus callosum. Most of the affected individuals have delayed psychomotor development and having seizures in many cases. Based on the referral note for this patient, mutations in WDR62 could be of relevance for the reported microcephaly. Additional clinical evaluation and investigations (EEG, MRI) are needed to determine the relevance of this variant. The here detected variants cause two alterations of conserved residues (p.Asp368Asn and p.Ala288Val). p.Asp368Asn alters a residue within the WD5 domain, whereas p.Ala288Val is located in between WD3 and WD4. The main function of all WD-repeat proteins is to coordinate multi-protein complex assemblies, whereas for the protein interactions these repeating units serve as a rigid scaffold. Both detected mutations have not been previously reported.

\section{CONCLUSION}

We have identified a novel compound heterozygous c.797C $>\mathrm{T}$ in exon 7 and c.1102G $>\mathrm{A}$ mutations in exon 9 of the WDR62 gene in two affected siblings of Saudi family with intellectual disability, speech impediments walking difficulty and primary microcephaly. We suggest that these type of studies are required to identify complete mutation spectrum related to primary microcephaly which will be useful for the precise clinical diagnosis of individuals suffering from disease in Saudi population.

Acknowledgement: This project was funded by the National Plan for Science, Technology and Innovation (MAARIFAH) - King Abdul-Aziz City for Science and Technology - the Kingdom of Saudi Arabia - award number (12-BIO3059-03). The authors also, acknowledge with thanks Science and Technology Unit, King Abdul-Aziz University for technical support".

Declaration of Interest: The authors declare no conflict of interest.

Grant Support $\mathcal{E}$ Financial Disclosures: This project was funded by the King Abdulaziz City for Science and Technology (KACST), Riyadh, Kingdom of Saudi Arabia, under grant number (12BIO3059-03).

\section{REFERENCES}

1. Woods CG, Bond J, Enard W. Autosomal recessive primary microcephaly $(\mathrm{MCPH})$ : a review of clinical, molecular, and evolutionary findings. Am J Hum Genet. 2005;76(5):717-728. doi: $10.1086 / 429930$.

2. Hussain SM, Marriam Bakhtiar S, Farooq M, Anjum I, Janzen E, Reza Toliat M, et al. Genetic heterogeneity in Pakistani microcephaly families. Clin Genet. 2013;83:446451. doi: 10.1111/j.1399-0004.2012.01932.x.

3. Miyamoto T, Akutsu SN, Fukumitsu A, Morino $\mathrm{H}$, Masatsuna $\mathrm{Y}$, Hosoba $\mathrm{K}$, et al. PLK1-mediated phosphorylation of WDR62/MCPH2 ensures proper mitotic spindle orientation. Hum Mol Genet. 2017;26:44294440. doi: $10.1093 / \mathrm{hmg} / \mathrm{dd} \times 330$.

4. Naseer MI, Rasool M, Sogaty S, Chaudhary RA, Mansour HM, Chaudhary AG, et al. A novel WDR62 mutation causes primary microcephaly in a large consanguineous Saudi family. Ann Saudi Med. 2017;37:148-153. doi: 10.5144/02564947.2017.148

5. Nardello R, Fontana A, Antona V, Beninati A, Mangano GD, Stallone $\mathrm{MC}$, et al. A novel mutation of WDR62 gene associated with severe phenotype including infantile spasm, microcephaly, and intellectual disability. Brain Dev. 2018;40:1:58-64. doi: 10.1016/j.braindev.2017.07.003. 
6. Roberts E, Jackson AP, Carradice AC, Deeble VJ, Mannan J, Rashid Y, et al. The second locus for autosomal recessive primary microcephaly (MCPH2) maps to chromosome 19q13.1-13.2. Euro J Hum Genet. 1999;7(7):815-820. doi: 10.1038/sj.ejhg.5200385.

7. Bilguvar K, Ozturk AK, Louvi A, Kwan KY, Choi M, Tatli $B$, et al. Whole-exome sequencing identifies recessive WDR62 mutations in severe brain malformations. Nature. 2010;467:207-210. doi: 10.1038/nature09327.

8. Nicholas AK, Khurshid M, Desir J, Carvalho OP, Cox JJ, Thornton G, et al. WDR62 is associated with the spindle pole and is mutated in human microcephaly. Nat Genet. 2010;42:1010-1014. doi: 10.1038/ng.682.

9. Murdock DR, Clark GD, Bainbridge MN, Newsham I, Wu YQ, Muzny DM, et al. Whole-exome sequencing identifies compound heterozygous mutations in WDR62 in siblings with recurrent polymicrogyria. Am J Med Genet. Part A. 2011;155A:2071-2077. doi: 10.1002/ajmg.a.34165.

10. Farag HG, Froehler S, Oexle K, Ravindran E, Schindler D, Staab T. Abnormal centrosome and spindle morphology in a patient with autosomal recessive primary microcephaly type 2 due to compound heterozygous WDR62 gene mutation. Orphanet J Rare Dis. 2013;8:178. doi: 10.1186/1750-1172-8-178.

11. Rupp V, Rauf S, Naveed I, Windpassinger C, Mir A. A novel single base pair duplication in WDR62 causes primary microcephaly. BMC Med Genet. 2014;15:107. doi: 10.1186/s12881-014-0107-4.

12. Bastaki F, Mohamed M, Nair P, Saif F, Tawfiq N, Aithala $\mathrm{G}$, et al. Novel splice-site mutation in WDR62 revealed by whole-exome sequencing in a Sudanese family with primary microcephaly. Congenit Anom. 2016;56:135-137. doi: $10.1111 /$ cga.12144.

13. Xu D, Zhang F, Wang Y, Sun Y, Xu Z. Microcephalyassociated protein WDR62 regulates neurogenesis through JNK1 in the developing neocortex. Cell Rep. 2014;6:104-116. doi: 10.1016/j.celrep.2013.12.016.

14. Yu TW, Mochida GH, Tischfield DJ, Sgaier SK, FloresSarnat L, Sergi CM, et al. Mutations in WDR62, encoding a centrosome-associated protein, cause microcephaly with simplified gyri and abnormal cortical architecture. Nat Genet. 2010;42:1015-1020. doi: 10.1038/ng.683

15. Chen JF, Zhang Y, Wilde J, Hansen KC, Lai F, Niswander $\mathrm{L}$, et al. Microcephaly disease gene $\mathrm{Wdr62}$ regulates mitotic progression of embryonic neural stem cells and brain size. Nat Commun. 2014;5:3885. doi: 10.1038/ncomms4885.

16. Bhat V, Girimaji SC, Mohan G, Arvinda HR, Singhmar $\mathrm{P}$, Duvvari MR, et al. Mutations in WDR62, encoding a centrosomal and nuclear protein, in Indian primary microcephaly families with cortical malformations. Clin Genet. Part-A. 2011;80:532-540. doi: 10.1111/j.13990004.2011.01686.x.

17. Stark AE. The genetic epidemiology of the form of microcephaly ascribed to mutation at the WDR62 locus. Ann Transl Med. 2016;4(15):281. doi: 10.21037/atm.2016.07.08.
18. Poulton CJ, Schot R, Seufert $\mathrm{K}$, Lequin $\mathrm{MH}$, Accogli A, Annunzio GD, et al. Severe presentation of WDR62 mutation: is there a role for modifying genetic factors? Am J Med Genet. Part A 2014;164A:2161-71. doi: 10.1002/ ajmg.a.36611.

19. Banerjee $\mathrm{S}$, Chen $\mathrm{H}$, Huang $\mathrm{H}$, Wu J, Yang $\mathrm{Z}$, Deng $\mathrm{W}$, et al. Novel mutations c.28G $>$ T (p.Ala10Ser) and c.189G $>\mathrm{T}$ (p.Glu63Asp) in WDR62 associated with early onset acanthosis and hyperkeratosis in a patient with autosomal recessive microcephaly type 2 . Oncotarget. 2016;7:7836378371. doi: 10.18632/oncotarget.13279.

20. Bacino CA, Dhar SU, Brunetti-Pierri N, Lee B, Bonnen PE. WDR35 mutation in siblings with Sensenbrenner syndrome: a ciliopathy with variable phenotype. Am J Med Genet. Part A 2012;158A:2917-2924. doi: 10.1002/ajmg.a.35608.

21. McDonell LM, Warman Chardon J, Schwartzentruber J, Foster D, Beaulieu CL, et al. The utility of exome sequencing for genetic diagnosis in a familial microcephaly epilepsy syndrome. BMC Neurol. 2014;14:22. doi: 10.1186/14712377-14-22.

22. Kousar R, Hassan MJ, Khan B, Basit S, Mahmood S, Mir A, et al. Mutations in WDR62 gene in Pakistani families with autosomal recessive primary microcephaly. BMC Neurol. 2011;119. doi: 10.1186/1471-2377-11-119.

23. Memon MM, Raza SI, Basit S, Kousar R, Ahmad W, Ansar M. A novel WDR62 mutation causes primary microcephaly in a Pakistani family. Mol Biol Rep. 2013;40:591-595. doi: 10.1007/s11033-012-2097-7

\section{Author`s Contribution:}

MIN conceived and designed the project.

MIN, AAA and MR performed experiments and confirmed these results.

MIN, MR and AGC analyzed and interpreted the whole-exome data.

MIN provided and interpreted phenotypic details for the patients.

AAA validated the data using Sanger sequencing.

AGC, KZ and MHA advised on the study design and writing of the manuscript.

MIN and MR wrote the manuscript.

Authors:

1. Muhammad Imran Naseer,

2. Mahmood Rasool,

3. Angham Abdulrahman Abdulkareem,

4. Adeel G. Chaudhary,

Center for Innovation in Personalized Medicine,

Faculty of Applied Medical Sciences,

5. Syed Kashif Zaidi,

6. Mohammad H. Al-Qahtani,

1-6: Center of Excellence in Genomic Medicine Research,

King Abdulaziz University,

21589, Jeddah,

Kingdom of Saudi Arabia.

Department of Medical Laboratory Technology,

Faculty of Applied Medical Sciences,

King Abdulaziz University,

21589, Jeddah, Saudi Arabia. 